\title{
LEYENDAS, RELATOS, MITOS Y CLIMA
}

\author{
POR
}

\author{
JORGE OLCINA CANTOS
}

Las sociedades antiguas han interpretado la historia del hombre y los elementos de la naturaleza mediante el recurso a relatos o narraciones simbólicas, historias narradas que, en suma, eran historias sagradas trasmitidas de palabra. Recordemos que el término mito, del griego $\mu \nu \xi_{0 \zeta}$, significa relato, narración, en contraposición a logos, discurso. Por tanto, un rasgo de las narraciones míticas, en cualquier civilización, es su transmisión oral. García Gual (1988) ha señalado que la oposición entre lógos y mýthos, era doble: el lógos es el discurso argumentado y verificable, el mýthos es el relato no verificable, tradicional. Y ello es así, porque en efecto, en el mito los referentes habituales (dioses, héroes, hombres del pasado, etc.) permanecen inaccesibles tanto a los sentidos como a la inteligencia. El mito no es un discurso argumentativo, porque estos referentes son descritos y puestos en escena como si se tratara de seres sensibles por un recurso sistemático a la imitación.

En estos relatos mitológicos se busca una razón última de la existencia del hombre en la tierra y de los fenómenos naturales que le rodean, entre los cuales los atmosféricos ocupan un importante papel. Los panteones de dioses de las civilizaciones antiguas están preñados de deidades que representan fenómenos y elementos naturales en un intento de encontrar explicación a dichos fenómenos. Gomme, en su

Jorge Olcina Cantos: Departamento Análisis Geográfico Regional. Universidad de Alicante.

Estudios Geográficos

Tomo LXI, 2000, n. ${ }^{\circ} 239$, abril-junio 
Folklore as an Historical Science, señala que cuando los salvajes se preguntan a sí mismos, como ellos seguramente se preguntan, de dónde viene el cielo, de dónde vienen los vientos, el Sol, la Luna, las estrellas, los mares, los ríos, las montañas y otros objetos naturales, ellos se responden en términos de buena lógica aplicada a un conocimiento deficiente.

Los mitos no se pueden juzgar con el espíritu crítico de la racionalidad contemporánea. Hay que entenderlos en el contexto en el que se gestan y de las sociedades a los que van dirigidos. No en vano se ha establecido, en la bibliografía especializada, la discusión sobre el carácter científico de los mitos. Al respecto Lewis Spencer (1997) señala que las repuestas primitivas a este tipo de preguntas forman parte no sólo de la naturaleza del mito, sino de la ciencia, ciencia primitiva, pero ciencia al fin, y añade que «estas respuestas no son menos científicas por tener la forma de cuentos». Con óptica actual, importa menos el grado de cientifismo de las explicaciones sobre las causas de los elementos atmosféricos, cuanto la misma preocupación por la explicación, ya entonces, de dichos elementos.

En la explicación de las preguntas fundamentales a la existencia y la naturaleza que rodea al hombre no debe sorprender que en este naturalismo religioso la explicación de los fenómenos atmosféricos encontrasen amplio tratamiento en sociedades plenamente condicionadas por los rasgos del tiempo y clima de cada región.

Dos características principales se pueden destacar de la relación entre relatos, mitos y elementos meteorológicos o climáticos:

- Dos de los cuatro elementos clásicos que componen la naturaleza (fuego, aire, agua y tierra) tienen relación directa con los elementos atmosféricos o climáticos, de ahí que no sorprenda la gran proporción de referencias a dichos elementos en las diferentes mitologías.

- El panteón suele estar coronado por la deidad que representa al Sol, el astro rey del que dependen todos los demás elementos y, asimismo, toda la maquinaria climática del planeta. Y junto a Sol los panteones están preñados de deidades relacionadas con las tormentas, el trueno, la lluvia, la sequía, el granizo y los vientos. 
Mitos y relatos en la explicación de los fenómenos atmosféricos

El $S o l$ es, sin duda, el elemento de la naturaleza que merece mayor atención en las narraciones mitológicas. Señala Spencer (1997) que el Sol es obviamente la fuerza natural que llama la atención, en primer lugar a los hombres, dado que es la fuente de la vida. En todas las mitologías el Sol ocupa, como se ha señalado, un papel destacado, si no el sitio principal del panteón. Spencer ofrece la siguiente explicación del ciclo solar que aparece plasmado en los distintos mitos del Sol: Después de que el Sol se haya elevado sobre la misteriosa oscuridad (El Caos), y después de haber abandonado a su primer amor, el amanecer, prosigue su curso, recuperando libremente su fuerza al proseguir en su barco o carro feroz hasta que, atravesados los cielos occidentales, encuentra al monstruo noche, con quien lucha y lo devora; entonces debe atravesar el Mundo Subterráneo, con todos sus peligros, hasta que consigue emerger una vez más en las puertas de la mañana.

Así en el panteón griego Helios es la personificación del astro solar que surge del Océano cada mañana y conduce un carro tirado por cuatro corceles para llevar la luz a los mortales. Esta misión es la que realiza $D a z b o g$, deidad venerada por pueblos eslavos, rusos, serbios, polacos y ucranianos. Los persas hablan de Atar, dios del fuego que guía el carro del Sol. Surya es el dios védico del Sol, el Gran Ojo de los cielos que todo lo ve y lo vigila que aparece representado sobre un carro de oro tirado por siete caballos.

En la exaltación del Sol, los griegos distinguían a Helios, dios solar natural, de Apolo, dios solar antropomorfo, la deidad más importante del Olimpo después de Zeus. Apolo es la divinidad solar por excelencia, el dios del fuego solar. Los griegos hablaban de Apolo Comeo, en referencia a su rubia cabellera cuyos cabellos simbolizaban los rayos del sol (vid. fig. núm. 1). El símbolo de Apolo es el carcaj o aljaba para portar las flechas. Los romanos adaptaron pronto a este dios, que denominaron también $\mathrm{Febo}$, venerando su poder sanador y sus atributos solares. El emperador Augusto lo convirtió en su dios tutelar. El Apolo de los pueblos galos era Abelión. Mithra era, por su parte, un dios solar, de origen persa, venerado por griegos y romanos, que personifica la luz y el calor solar. Se le representaba como un jovencito con capa y gorro frigio junto a dos jovenes, Cautes y Cautópates, símbolos del sol naciente y poniente, respectivamente. Los hititas veneran a Istanus, per- 


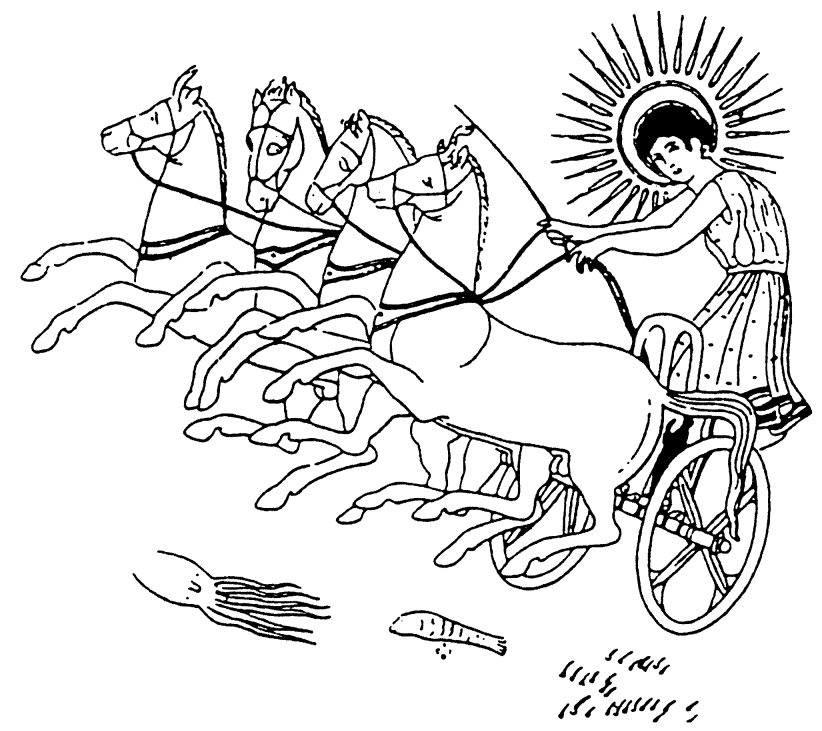

Fig. 1. Apolo era el Dios del fuego solar en la mitología griega y romana. Se le representa con una corona de rayos sobre su cabeza, alusiva de su condición de máxima deidad solar (ilustración tomada de Humbert, J. Mitología griega y romana. Gustavo Gili, Barcelona, 1997).

sonificación del Sol en su recorrido diurno. Los japoneses hablan de Wakahiru-Me, diosa solar del alba, a la que califican de «floreciente señora del Sol».

Sea como fuere, el Sol ocupa siempre lugar destacado en la práctica totalidad de panteones. El propio Zeus griego, aunque no es propiamente un dios solar, sí es «señor de la luz del día» que procede del Sol. Amaterasu, la más importante deidad del panteón japonés, es la diosa del Sol, todavía venerada en la actualidad como fundadora de la familia imperial. El mito de Amaterasu relata también el desarrollo de eclipses solares en relación con los ritos agrícolas del antiguo Japón: Amaterasu, para huir de su hermano Susanowo, dios de la Tempestad, se escondió dentro de una gruta, llevándose consigo al Sol, privando a la Tierra de su beneficioso esplendor. La diosa se decidió a abandonar la gruta cuando la diosa de la Danza y la Sonrisa, Amano-Uzume, la persuadió para que saliese de la cueva, para llevar sobre la Tierra su benéfica luz vivificadora 
Shamash es el díos solar de Babilonia en tiempos de Hamurabi, es, al mismo tiempo, dios de la sabiduría, porque en su recorrido por el cielo, del orto al ocaso, todo lo ve y todo lo sabe.

Los fenicios veneraban al dios solar Aglo Bol. Los eslavos a Suaixtix. Los sintoístas veneran en la ciudad de Ise a Dainzu No Rai, ídolo solar representado sobre una vaca y encerrado en un tabernáculo construido en una cueva llamada Avvano Matta, «Costa del cielo».

En África, Izuwa es el dios del Sol venerado por algunas tribus situadas a lo largo del río Zambeze, en Zimbabwe. Los cauna de África del Sur veneran a Modimo. Orun es el dios del Sol de los indígenas yoruba de Nigeria. En Oceanía, los maoríes de Nueva Zelanda veneran al dios sol Tane.

El Sol es principal objeto de culto en el Egipto antiguo. En Heliópolis se venera el Sol en sus tres aspectos: Jepara es el Sol de la mañana, $R a$ el de mediodía y Atum el Sol de la tarde. La barca solar navega en el océano de aguas primordiales (Nun) que rodea la tierra. De día, en el cielo, $R a$ brilla, pero cada vez menos vigoroso. $\mathrm{Y}$ de noche, bajo tierra, es debilitado y amenazado. Pero bajo tierra, en el Nun tenebroso, un Ra debilitado recuperará la fuerza de su renacer para reaparecer como la Primera Mañana.

Con el paso del tiempo, la deidad natural, será adoptada por los faraones como soporte divino de su poder terrenal. Y surgirán luchas entre distintos poderes por imponer su culto bajos distintas formas. Así, en el Imperio Nuevo Amenofis IV introducirá el culto a Atón, el disco solar, y trasladará la nueva capital a Akhenaton, en la actual Tell el Amarna, como reacción al culto tebano de Amón. Ramses II, en la dinastía XIX, se declarará $R a$, «señor del cielo sobre la tierra».

El poder absoluto del Sol venerado por los aztecas llevaba a este pueblo a dividir la evolución de la humanidad en Eras Solares para referirse a cada uno de los cinco Soles en cuyo desarrollo tenía lugar una civilización que culminaba en una catástrofe irremediable. Después de los apocalipsis que culminan las primeras cuatro eras se estableció el quinto Sol, el actual, que recibe el nombre de Tonatiuh, cuya cabeza aparece representada en el centro de la Piedra del Sol aparecida entre las ruinas de Tenochtitlán. Los mayas veneraban a Kinich Ahau, dios del Sol poniente

Los incas basaban sus creencias en la veneración del Sol. El propio nombre «inca» significa pueblo del Sol. Inti era el dios Sol; su calor be- 
neficiaba a la tierra andina y permitía la maduración de las plantas. En su honor celebraban, en el solsticio de verano, la festividad de Inti Raymi, en la que se encendía una hoguera donde se quemaban la víctima del sacrificio, hojas de coca y maíz. Además de esta festividad, los cuatro hitos del recorrido del Sol (solsticios y equinoccios) se indicaban por medio del intihuatana, una gran roca, coronada por un cono que hacía sombra en unas muescas de la piedra.

Spencer ve reminiscencias del mito del dios Sol en el cuento del rey Arturo. Éste posee una espada mágica como la mayoría de héroes solares y mata a varios dragones, como Apolo dio muerte a los Cíclopes. Incluso sugiere que la referencia a la tabla redonda no es sino una referencia al disco solar.

El poder de la deidad solar sobre los hombres viene expresado en el mito de Ícaro, hijo de Dédalo, que, desoyendo los consejos de su padre y embriagado del poder que le otorgaban las alas de cera y plumas que éste le había fabricado para poder escapar del laberinto en el que habían sido confinados por el rey cretense Minos, se acercó tanto al Sol que la cera se fundió, las plumas se desprendieron y, en su vuelo, se precipitó al mar Egeo, no lejos de la isla de Samos, dando nombre al pequeño mar, en el Mediterráneo oriental, que se extiende entre dicha isla y las de Quío, Patmos, Naxos y Micona.

La aparición de la primera luz del día también encuentra explicación en los relatos mitológicos en el mito de la aurora. Los griegos veneraban a la diosa preolímpica Eos que era la encargada de anunciar el día. Eos era hermana de Helios y de Selene (la Luna), y precedía en el cielo al primero para dar la luz a los hombres. De su unión con el titán Astreo concibió a los Astros y los vientos principales. Homero habló de Eos como la diosa matinal, «la del peplo de azafrán» que regula la sucesión de los días y de las hazañas bélicas cada vez que abra, con sus rosados dedos, las puertas del cielo al carro del Sol (vid. fig. núm. 2). Este mito tiene su versión romana en la diosa Aurora. Los eslavos veneraban asimismo a Zoria, la Aurora, que en su trabajo diario de apresurar los caballos del Sol era ayudada por la estrella Vetcherniaia. Los eslavos distinguían dos Zorias, ambas al servicio del Sol, para abrir (alba) y cerrar (ocaso) su palacio. Los japoneses veneran a Marisi-Ten, deidad de la aurora de origen hindú.

Existen una serie de deidades responsables de los fenómenos atmosféricos con carácter general. Es el caso del dios egipcio Reshep. Los

$$
-306-
$$




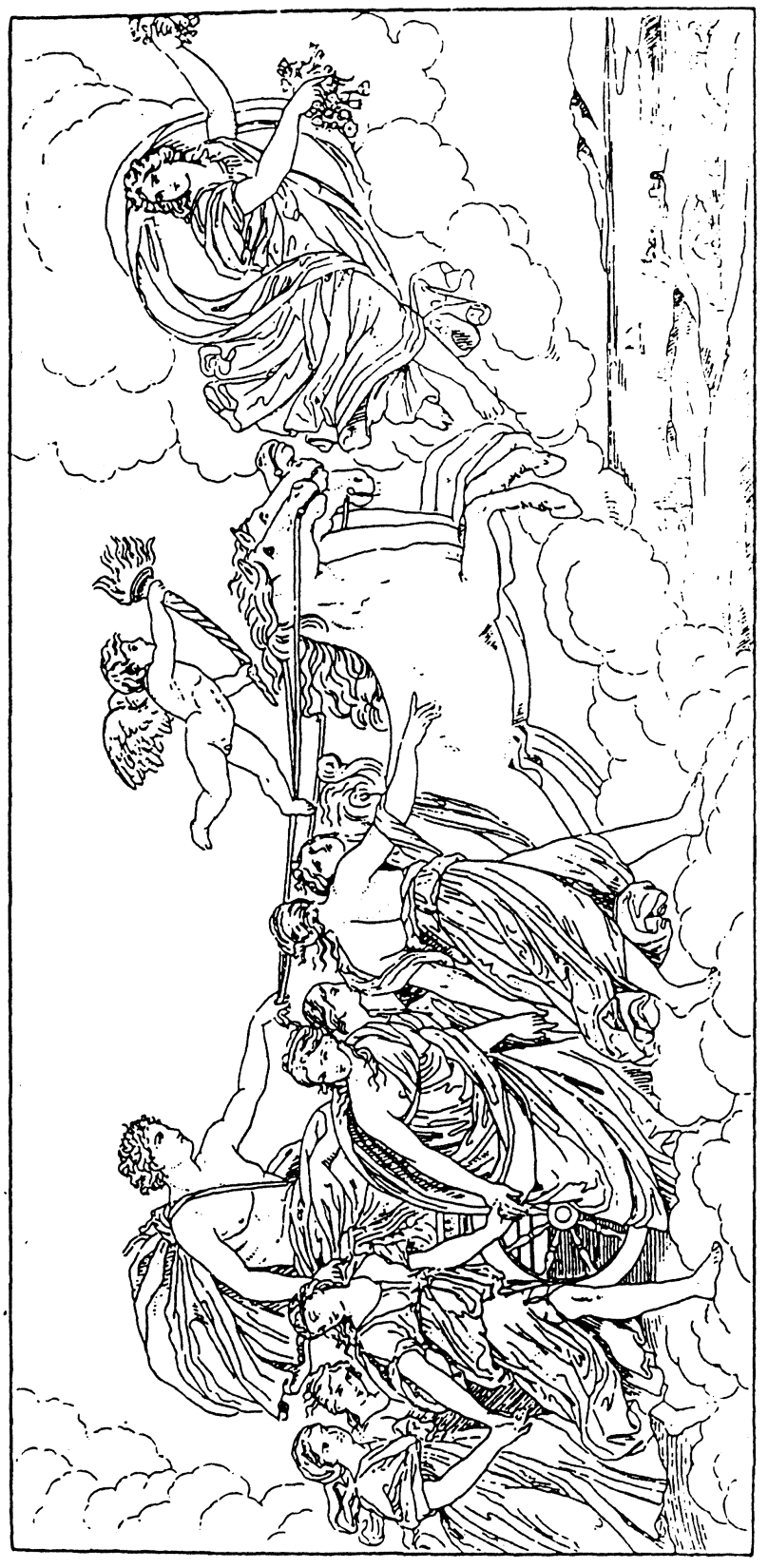

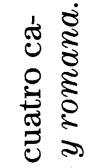

ํํำ

ํำ है

.

ำ

$\Xi \because$

(1)

宽 总

용

号

की 웡

సี हี

원

워ำ

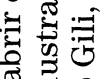

要

ช

:

ชี

हृँ

旅

떵 웡

की :

$\begin{array}{ll}\infty & 0 \\ 0 & 0 \\ 0 & 0 \\ 0 & 0 \\ 0 & 0\end{array}$

敢

ชี

ง

它

$-307-$ 
eslavos veneran al dios del tiempo atmosférico Dogoda, responsable además de los vientos suaves, que se asimila generalmente al Céfiro griego. Dattas es una deidad menor de los asirios encargada de las manifestaciones atmosféricas. En China, Lei-Kong es el dios que gobierna las manifestaciones atmosféricas.

En el panteón budista existen los llamados Guardianes del Cielo, venerados en China y Japón que tienen como misión principal vigilar el cielo. Se les venera como genios tutelares y sus imágenes se colocan en los vestíbulos de los templos orientadas hacia la zona del cielo que custodian. Los chinos los llaman Tien-Wang y los veneran además como patronos de las estaciones y protectores de los cuatro elementos principales (aire, tierra, agua y fuego). Así, Tuo-Weng, vigila el norte del cielo y es el genio del otoño, Tseng-Cang vigila el sur y es el dios de la primavera que viene representado con un paraguas mágico en la mano, Che-Kuo vigila el este y es el genio del verano, y Kuang-Mu gobierna el oeste y es el espíritu del invierno. Los japoneses los denominan Sitenno y son, respectivamente, Bishamon, Zoco, Gikoku y Komoku.

Las manifestaciones violentas del tiempo atmosférico también encuentran representación en las diferentes mitologías. En la mitología griega, Aelo o Licotoe, una de las Harpías o Arpías, es la responsable de las tempestades. Estos monstruos fabulosos, hijas de Poseidón y Gea, representan la furia de las tempestades.

Tempestad es la alegoría romana representada por una mujer de expresión iracunda, situada bajo densas nubes en un cielo tempestuoso. De sus manos salen granizos que matan los árboles y destruyen las cosechas. La Tempestad tenía un templo levantado cerca de la puerta Capena en Roma.

Para los sumerios, Enlil es el dios de las tempestades, los vientos y las lluvias. Según el mito acadio del diluvio, Enlil encabezó a una serie de divinidades dispuestas a hacer caer el diluvio universal y así castigar a los hombres, culpables por no haber hecho sacrificios a los dioses y no haber celebrado los ritos del año nuevo. Adad es el rey asirio-babilonio venerado como dios de la lluvia, del viento y de las tempestades. Como deidad de las tempestades asumió el nombre de Ramman, el rugiente. Según la tradición, $B a a l$, principal dios de las fuerzas naturales, le encargó que desencadenase el diluvio sobre la tierra. Teshup es el dios asirio del huracán y la tempestad. 
Los ganda de Angola veneran al dios Mukasa, deidad de la tormenta. Nenonir es el dios de tempestad venerado por algunas tribus indígenas de África central.

En algunas islas de Oceanía se venera al espíritu supremo Apa Hau, gobernador de las tempestades. Guabancex es, por su parte, el dios del agua y de las tempestades, venerado por los indios taínos de Haití.

La lucha del hombre contra las tempestades viene ejemplificada en la Odisea, donde Homero relata las hazañas del héroe Ulises. En su viaje de regreso a Ítaca, tras la guerra de Troya, Poseidón le fue hostil y sembró de dificultades su viaje. Una tempestad empujó a Ulises y sus compañeros a las costas de Tracia, al país de los crueles cicones. En su periplo por las islas de Eolo, el dios les ofreció su ayuda, pero la imprudencia de algunos miembros de la tripulación desencadenó una terrible tempestad que les condujo a Campania, a la tierra de los lestrígones. Tras consultar sobre su suerte al adivino Tiresias, en el país de los cimerios, Ulises reemprendió viaje de vuela a Ítaca pero Zeus desencadenó otra terrible tempestad en la que perecieron todos sus compañeros, castigados por haber devorado los bueyes sagrados del Sol de la isla de Trinacia. En otro pasaje, tras abandonar la isla de Calipso, una nueva tempestad arrojó a Ulises a las playas de Feacia, donde fue acogido por los reyes Alcínoo y Arete y su hija Nausícaa, que le facilitarían el definitivo regreso a Ítaca.

En sentido totalmente contrario, esto es, como mito que hace alusión a tiempo bonancible se encuentra el relato de Ceix y Alcíone. La pleyade Alcíone, hija de Eolo y Enereta, se casó con Ceix, rey de Traquina. Ceix, tras la muerte de su hermano Dedalión y desoyendo los consejos de su mujer, fue a Claros a consultar al oráculo de Zeus la manera de devolver a la vida a su propia madre; durante el viaje la nave naufragó y $A l$ cíone soñó con el cadáver de su marido llevado por las olas a la orilla. Cuando despertó corrió a la playa y se encontró, en efecto, el cuerpo sin vida de Ceix. Desesperada se arrojó al mar. Los dioses s e apiadaron y trasformaron a los dos esposos en alciones o martines pescadores, de los que se creía que construían nidos flotantes, para cuya protección, Eolo, padre de Alcíone encalmaba los vientos durante siete días antes y después del solsticio de invierno. Los ingleses hablan de «halcyon days» para hacer alusión a un tiempo tranquilo y apacible.

Son numerosas las deidades relacionadas con truenos, relámpagos y destellos. Estos tres fenómenos, integrantes de un mismo meteo- 
ro, el rayo, tienen trato importante en los relatos mitológicos por la espectacularidad que produce su aparición y porque suelen ir vinculados a tormentas y lluvias, consideradas don vivificante entre los diferentes pueblos. En muchos pueblos la piedra de perdernal simboliza al trueno, debido a que el fuego procede del pedernal. Las deidades más importantes de los panteones tienen incluso su aspecto «tonante» como una característica más de su poder omnímodo. Es el caso de Zeus Cataba$t e$, en el panteón griego, expresión del dios Zeus que desciende a la Tierra con la apariencia de rayo y trueno. De hecho el escudo de Zeus, denominado Égida, forjado por el dios del fuego Hefesto, es irrompible y tiene la cualidad de desprender los rayos que desencadenan las tempestades. Es interesante recordar el relato de Prometeo, hijo del titán Japeto y de la oceánide Clímene, que robó a Zeus el fuego del cielo para que fuera usado por los hombres, escondiéndolo en el tallo de una planta, transmitiendo así la técnica de la metalurgia. En la teogonía romana, Júpiter merece los calificativos de Fulgor aut Fulminator cuando se representa como dios de los rayos, y de Tonans, como dios del trueno; el ruido del trueno procede de los cerrojos olvidados para él por los titanes en las entrañas del Etna. En el panteón germano, Thor, hijo del dios supremo Odin, es el dios del trueno y del relámpago y, por extensión, de la guerra; su martillo, Mjolnir, simboliza el trueno y las flechas que envía son los relámpagos. Su misma barba roja representa el relámpago. El sonido del trueno de Thor es producido por el golpe de su martillo o el estruendo de las ruedas de su carro conducido por cabras. Como dios del trueno que lleva asociado asimismo las tempestades y las lluvias, Thor es el patrono de las cosechas, y por tanto amigo de los campesinos. En la mitología eslava se venera a Perkun (Perun) como divinidad del trueno, sobre todo en Polonia, Pomerania y los países bálticos. Los lituanos le denominan Perkunas. Para su veneración el altar tenía un fuego permanentemente encendido en alusión al rayo de donde procede el fenómeno acústico. Para los hindúes Aksobhya es uno de los cinco Dhyanibuda, esencia pura emanada del Buda primordial, que vigila el cielo de oriente y tiene como símbolo el rayo. Los arameos veneraban a Hadad, patrono de los rayos y los vientos huracanados, que se asimila al dios asirio Adad y al que los cananeos llamaban «Hadad dios-huracán». El pueblo asirio luvi veneraba a Santas como dios del rayo y la tempestad. En el panteón nipón, Ika-Zuchi, venerado en el monte Mimoro, es el dios serpiente más conocido con el nombre de $M i$-Ua, que re- 
presenta al rayo y Raiden es el dios del trueno. Por su parte, Kami-Nari, es una de las antiguas divinidades japonesas de los fenómenos atmosféricos que se asocia también al trueno. Topan es asimismo una deidad del trueno. Cuando está enfadado corre por el aire sacudiendo la clava y provocando violentas tempestades. Se le representa sobre un altar de bronce con forma de nube, armado con un yelmo coronado y con el mentado palo o clava. Los chinos veneran a Lei-Kong, dios de las manifestaciones atmosféricas y del trueno; lleva colgado tambores en la cintura, que golpea para producir el ruido del trueno; en esta misión recibe ayuda de su mujer Tien-Mu, diosa de los rayos.

En África algunas tribus de Mozambique veneran a Tilo dios del cielo, el trueno y la lluvia. En América, Chac es la divinidad maya que gobierna los truenos y rayos; se le equipara al Júpiter pluvio de los romanos. Haokan es el dios del trueno entre los indios sioux. Chuchavi$r a$ es el dios del fuego, del trueno y del arco iris de los indios chibcha del norte de Colombia. Eliseé Reclús en su Viaje a la Sierra Nevada de Santa Marta, al referirse a la religiosidad de las tribus goajiras, de Colombia, señala que «una sola práctica prueba que admiten la existencia de un ser supremo: cuando el trueno retumba, arrojan en el aire tizones encendidos y dan grandes gritos, como para devolver al espíritu de la tempestad voz por voz, rayo por rayo». En el panteón azteca los Tlalo$q u e$, hijos de Tlaloc y de Chalchiuhtique eran las divinidades encargadas de producir rayos y truenos. Hino es el dios del trueno de los iroqueses. Algunas tribus de los Andes imaginan que la tormenta reside en la cima de las montañas, rodeado de nubes cuyos labios rojo fuego personifica al trueno. Otras tribus representan al trueno como un pájaro, cuyo batir de alas causa su retumbar. Yetl es el dios trueno de los tlinkeetes, que adoptó las alas de una grulla sobrenatural.

En Oceanía, los indígenas de San Cristóbal y de las islas Salomón veneran a Agunua, mítica serpiente creadora del trueno y del resto de fenómenos atmosféricos. Whai Tiri es la diosa del trueno entre algunas tribus indígenas de la Polinesia Central.

El viento es otro elemento atmosférico ampliamente venerado en las diferentes culturas. En el panteón egipcio $S h u$, es el dios del aire, representado con figura humana con una pluma sobre la cabeza mientras sostiene el viento. Cada uno de los vientos principales tenía su representación en el panteón; así, Henkhisesui es el viento del este, Huzia$n i$ es el viento del oeste, Merit es el viento del norte. 
Los griegos veneraban a Eolo, nieto de Hépotas que habitaba en la región central de las islas volcánicas Eolias, al norte de Sicilia, donde tenía encadenados los vientos en un antro profundo, gobernándolos con absoluto dominio, permitiendo unas veces que corrieran sueltos por el mundo, o bien, encerrándolos en cavernas o en odres de piel, según su capricho. Este dios juega un papel principal como excitador o apaciguador de tempestades. A él se dirige Ulises para obtener una navegación feliz. En el canto X de la Odisea se cuenta que Eolo entregó uno de estos odres para ayudarle a regresar a Ítaca cuando su barco quedó inmovilizado por una calma chicha, pero los compañeros del héroe lo abrieron, por curiosidad, creyendo que había oro cuando este dormía. Se desencadenó, entonces, una violenta tempestad y los vientos dirigieron las naves de Ulises hacia las islas Eolias. Eolo, temiendo granjearse la enemistad de los dioses, se negó en lo sucesivo a ayudar a Ulises.

En el canto I de la Eneida la diosa Juno implora el auxilio de Eolo para dispersar la flota de los troyanos e impedir que Eneas desembarque en Cartago. Eolo aparece representado empuñando un cetro, símbolo de su autoridad, y a su lado se agitan los vientos, genios inquietos y turbulentos. Cada uno de los vientos era considerado, asimismo, una deidad. Así Bóreas es el viento del norte, el viento Aquilón de los romanos, que vive habitualmente en Tracia y desde allí esparcía sobre las comarcas vecinas el frío, la nieve y las tempestades. Bóreas, el más poderoso de los vientos, raptó a la hija de Erecteo, Oritia, de la que tuvo varios hijos, Quíone (la nieve), Aura (la brisa), y Zetes y Calais, llamados los Boréadas. Euro, que es el viento del sureste, hijo del titán Astreo y de Eso, exhalaba alternativamente humedad y sequedad. Se creía que procedía de Etiopía y por ello se le representa con la piel oscura. Hesíodo lo denomino $A r$ gestes y los romanos Volturno, término del que procede la palabra castellana bochorno. Noto es el viento del sur, también llamado Austro y Ostro, que traía la niebla y la lluvia. Céfiro o Zéfiro es el viento del oeste, unas veces agradable y otras lluvioso, que anuncia la llegada de la primavera. Es, en suma, el viento de poniente. Los romanos lo denominaron Favonio. Junto a estos cuatro vientos principales estaban los vientos secundarios: Áfricano o Libetio, Subsolano o Apoliotes, Cecias o Greco, viento del noreste, Esquirón, del oeste noroeste (vid. figura $\mathrm{n}^{\circ} 3$ ).

Por su parte, el viento suave, que representa la brisa, aparece personificado, según Spencer (1997), en el mito de Pan, el dios silvestre originario del Ática que respira melodía a través de su flauta de caña. 
Todos los panteones mitológicos tienen su dios o dioses del viento. Así el correspondiente dios Eolo en el panteón persa es el dios Bad; Niördhr es la divinidad nórdica de los vientos. Adad es el dios mesopotámico del viento. Vayu es el correspondiente de los vedas, con el rasgo de representar los vientos más suaves, en contraposición con los $M a$ ruts, que, como reza el Rik o primer Veda «hunden todas las casas celestes y terrestres con su fuerza».Shina-Tsu-Hiko es el dios japonés de los vientos. En tiempo de la creación tuvo la tarea de llenar el vacío que existía entre la Tierra y el Cielo. En China, la divinidad Feng-Po gobierna los vientos y es representada por un anciano barbudo que monta un odre con un abanico en la mano que mueve para generar aquéllos.

Abutto es el ídolo japonés al que se dirigían los marineros antes de emprender la navegación para obtener vientos favorables. Para los eslavos Warpulis es el dios de los vientos y de las tormentas, que forma parte del séquito de la máxima divinidad Perkun. En el brahmanismo, Niruti es uno de los ocho protectores invisibles de los ángulos del cielo, que está a cargo de la región suroccidental donde domina los vientos. Apa Hau es el dios de los vientos para los indígenas de Polinesia septentrional. O Hina es la diosa maori del aire que junto al dios, Taaroa engendró el arco iris.

Cuchavara es el señor de los vientos y del arco iris entre pueblos indígenas de Colombia. Ecalchot es el dios del viento venerado en algunas tribus de Nicaragua. Ga Ho es el gigante dios de los vientos de los indios iroqueses de América del Norte. Meuler es el dios araucano del viento. Salinobia es la divinidad de los vientos para el pueblo norteamericano de los zuñi.

Dentro de la mitología griega resulta interesante el personaje de Tifón o Tifeo, monstruo fabuloso, hijo de Gea y Tartaro, que pertenece al linaje de las divinidades primordiales nacidas de la Tierra, contra las que Zeus tuvo que enfrentarse para establecer el orden olímpico. Según la leyenda, Tifón tenía cien cabezas de dragón y una fuerza invencible. Zeus se enfrentó a él cuando intentó destronarlo, pero no consiguió acabar con él. Los otros dioses, aterrorizados, huyeron a Egipto bajo la apariencia de animales. Tifón los persiguió y los egipcios lo llamaron Tifeo, pues vieron en él el viento furioso del desierto que reseca los campos. Zeus consiguió al fin destruirlo sepultándolo vivo bajo el Etna, de donde a veces salen todavía las llamas y los rugidos del monstruo prisionero. La palabra tifón designa actualmente un ciclón tropical muy violento. En 
japonés, Tai-Phou significa, viento fuerte, y con esta denominación se llaman los ciclones tropicales que afectan el Mar de la China.

En relación con vientos violentos hay que destacar, asimismo, el mito de Huracán, uno de los cuatro sostenedores del mundo adorado por los pueblos indígenas de Guatemala. Huracán es el dios primordial de la Creación, el «creador del cielo» que se revela en las cuatro manifestaciones que son también sus hermanos: el mismo Huracán, o sea, el huracán atmosférico, el Cuculhá Huracán, o el rayo, el Cipi Cuculhá, o trueno y el Razá Cuculha o el rayo de color azul. Huracán es el dios terrible de las tempestades que domina sobre los otros dioses. Por extensión esta expresión denomina, en la actualidad, a los ciclones tropicales que se desarrollan en el ámbito del Caribe. En Japón existe la leyenda de Hira, ciclón devastador de las orillas del lago Biwa protagonista de una historia de amor que se asemeja a la fábula griega de Leandro y Hero, ésta ambientada en el estrecho de Helesponto. Una muchacha japonesa que vivía a orillas de dicho lago se enamoró del guardián del faro de la orilla opuesta. Para reunirse con su amante la muchacha atravesaba el lago de noche, remando sobre una barca siguiendo la luz del faro. El idilio se prolongó durante varios meses hasta que el enamorado, ansioso de descubrir si ella era realmente una mujer enamorada o una criatura diabólica, apagó una noche la luz del faro y dejó que ella se perdiera entre las nieblas del lago. La muchacha vagó perdida implorando la ayuda de su amante; agotada, la chica se dejó ahogar maldiciendo al joven . El ciclón Hira la oyó, se desencadenó inmediatamente y, después de haber puesto a salvo a la chica, despedazó al guardián desconfiado, el faro y la orilla.

El mito del gran diluvio está representado en la mayoría de culturas. Estos relatos cuentan cómo los cielos o la Tierra, o ambos, son sumergidos por las aguas y todas las cosas vivientes ahogadas, con excepción de un individuo o una familia que son favorecidos por los dioses. En el mito de la inundación universal un ser supremo castiga a los hombres por haber descuidado sus obligaciones para con los dioses. Es un juego de destrucción, caos y renovación en búsqueda de comportamientos más éticos por parte de los hombres. Se entiende como símbolo de grandes cambios políticos o renovaciones étnicas por ser un punto cero a partir del cual se puede volver a construir una historia local, como ocurre en Mesopotamia. Así en las historias políticas mesopotámicas del II milenio a. J. C. Las listas de reyes se elaboran tomando el Diluvio como pun- 
to de inflexión y se habla de reyes anteriores al diluvio y reyes posteriores a él. Tiene, pues, el valor de calendario. Si bien se ha señalado, para el ámbito mediterráneo, que los mitos del diluvio pueden estar traduciendo episodios locales de lluvias torrenciales, condignos a las condiciones de los climas mediterráneos, períodos pluviales del cuaternario tardío en relación con fases frías en el sector de contacto entre latitudes medias y subtropicales o bien el aumento de nivel marino, en áreas costeras, que siguió al último postglaciar wurmiense. Sea como fuere, lo cierto es que estos relatos revelan la inquietud de unos pueblos por transmitir, en la memoria colectiva, los efectos devastadores de episodios de lluvias intensas.

En el orbe occidental es bien conocida la versión bíblica del diluvio a través del mito del arca de Noé, que se contiene en el libro del Génesis. Viendo Jehová la mucha malicia de los hombres sobre la Tierra, decidió poner fin a tal situación. "Y yo, he aquí que yo traigo diluvio de aguas sobre la tierra para destruir toda carne en que haya espíritu de vida debajo del cielo; todo lo que hubiere en la tierra morirá». Tan sólo Noé halló la gracia divina al recibir el encargo de construir una gran barca, donde embarcarían él, su mujer, sus hijos « y de todo lo que vive, de toda carne, dos de cada uno meterás en el arca para que tengan vida contigo». El mito señala que «siendo Noé de seiscientos años, el diluvio de las aguas fue sobre la tierra» y añade que «el año seiscientos de la vida de Noé, en el mes segundo, a los diecisiete días del mes, aquel día fueron rotas todas las fuentes del grande abismo y las ventanas de los cielos fueron abiertas». Las lluvias duraron «cuarenta días y cuarenta noches», cifra de gran significado, asimismo, en el cristianismo y las aguas sobre la tierra «ciento y cincuenta días». Pasado este suceso Dios habló a Noé para pedirle que sacara del arca a su familia y a los animales que había embarcado. Tras los sacrificios ofrecidos por Noé a Jehová, dijo Dios «no tornaré más a maldecir la tierra por causa del hombre».

En la tradición hebrea el relato del diluvio universal se completa con el mito de $O g$, gigante que se salvó de la inundación nadando detrás del Arca de Noé con el morro apoyado en la popa. Noé lo alimentó a través de una claraboya, no tanto por compasión como para demostrar a los hombres que repoblasen el nuevo mundo hasta qué punto era grande el poder de Dios al crear a tales monstruos. La leyenda cuenta que $O g$ juró a Noé, por gratitud, que se convertiría en su esclavo, pero pasado el di- 
luvio el gigante olvido el juramento y retomó el camino del mar. Moisés mataría al monstruo $O g$ con posterioridad.

El personaje de Noé y el pasaje del diluvio merecen tratamiento, con denominación varia, en las distintas mitologías. Así, el Noé sumerio es Ziusudra; los babilonios hablan de Xisuthros; los acadios veneran el mito de Nisir, monte sagrado sobre el cual encalló el arca construida por Utnapishtim, durante el diluvio provocado por el dios Enlil. Utnapishtim aparece mencionado en el poema de Gilgamesh, héroe mítico de los asirios, nieto de Utnapishtim al que éste pidió el secreto de la inmortalidad.

Para los hindúes el hombre salvado de las aguas se nombra Manu, hijo del dios Sol Vivasvat; los persas lo llaman Yima. Entre las tribus americanas también existe el mito del diluvio y el heroé que se salva de la inundación. Así, los indios Ahts, de Vancouver, hablan de Wispo$h a h p$; los indios algonquinos, de Michabo; los Antis, de Brasil, de $Y u$ rukares, los Arawaks, de Sigu. El héroe maya que escapó del diluvio que destruyó el cuarto mundo es Coxcoctli.

La mitología griega tiene también sus mitos del diluvio. Así se habla del «diluvio de Ogiges», hijo de Poseidón, en cuyo reinado se produjo la inundación de una parte de Beocia y Ática por desbordamiento del lago Copais. Este diluvio es anterior, según la tradición, al que relata la leyenda de Deucalión y Pirra, tenidos como los antepasados de todos los griegos. El mito cuenta que Zeus, irritado por el comportamiento de los hombres, decidió destruir la raza humana sepultándola bajo las aguas. Sólo Deucalión y Pirra fueron considerados por Zeus merecedores de escapar al diluvio. Prometeo, padre de Deucalión, les aconsejó que construyeran un arca, en la que flotaron a la deriva durante nueve días antes de alcanzar los montes de Tesalia, no lejos del monte Olimpo. Salvados del diluvio, Hermes les concedió un deseo. Decaulión le solicitó compañeros que acabasen con su soledad. Para repoblar la Tierra, Zeus aconsejó a los esposos que arrojaran «los huesos de su madre» detrás de ellos. Deucalión comprendió que se trataba de Gea, la Madre Tierra, cuyos huesos son las piedras. Así, velándose el rostro por respeto, Deucalión y Pirra recogieron las piedras que lanzaron por encima de sus huesos sin girarse. De este modo, Deucalión y Pirra tuvieron a sus hijos Doros y Eolos, que junto a los nietos Aqueo y Ion, adivinan las tribus de la antigua Grecia. El mito de Deucalión y Pirra corresponde al de Bergelmir e Ymir en el panteón escandinavo. 
Más antiguo que los mitos mencionados y en relación, no tanto con diluvios cuanto con el poder benéfico de la crecida fluvial, los egipcios veneraban a Hapi, el dios Nilo que anualmente aportaba la fertilidad natural a las tierras ribereñas del Medio y Bajo Egipto, en forma de sedimentos y fertilizantes naturales. Hapi era representado como un hombre bien alimentado, de pechos colgantes, vientre pronunciado sostenido por un cinturón y sandalias en los pies, lo que era signo de riqueza. Sobre la cabeza ostentaba una corona de plantas acuáticas. Sus manos portaban símbolos de vida o sostenían una mesa de ofrendas repleta de pescados, patos, ramos de flores y espigas. Hay que recordar que el ciclo anual de los egipcios no venia marcado por el calendario astronómico, sino por el año agrícola, es decir, con la producción de cosechas que estaban en función de la fecha en la que ocurría la avenida benéfica del dios Nilo.

La veneración de dioses o ídolos de la lluvia en los pueblos primitivos está en intima relación con la aparición de épocas secas y el ulterior desarrollo de peticiones implorando la beneficiosa precipitación en los campos, a modo de rogativas pro pluviam en el orbe católico.

Los griegos veneraban al dios lunar Men, señor del Cielo y del Más Allá que presidía la agricultura y las lluvias. Los romanos daban al dios Júpiter el apelativo de pluvio en los períodos de sequía para reclamar de él el beneficio de la lluvia restauradora. Mot es el dios palestino que personifica a la sequía, hijo de $E l$. Según la leyenda, $M o t$ fue enemigo del dios fenicio de las Fuentes y de los Arroyos, con el que mantenía todos los años un duelo en el que siempre resultaba perdedor. El mito destaca, pues, la victoria de la humedad sobre la sequía y el calor estival. Los persas veneraban a la estrella Tishtrya como divinidad que aportaba la lluvia beneficiosa y que mantiene una lucha eterna con Apaosha, genio responsable del desarrollo de sequías. Baal es el dios semita de la lluvia.

$\mathrm{Yu}-\mathrm{Si}$ es la divinidad atmosférica china responsable de las lluvias benéficas, que aparece representada con un vaso en la mano del que hace manar el agua agujereándolo con su espada. Por su parte, Tanquin es el genio que dispensa la lluvia vivificante. Kugaku es la deidad japonesa de la lluvia.

Las tribus indígenas del Yucatán veneran a la diosa Cuerevaperi en épocas secas para solicitar las precipitaciones. Los incas veneraban a Apu Illapua como dios dador de la lluvia. Por su parte, en el Golfo de 
México los totonachi adoran al dios Tajín, responsable de la lluvia y del trueno.

En África, Leza es el ente supremo venerado por los bantúes del norte de Zimbabwe como divinidad responsable de las lluvias fecundantes. Según esta creencia los rayos serían producidos por la apertura de su boca y el trueno por sus palabras; el arco iris sería una rama coloreada en donde Leza se posa tras la lluvia. Los masai de África suroriental veneran al dios Ngai, creador de todas las cosas, que castiga a los malos con la sequía y a los buenos con la lluvia. El dios Ngai manifiesta su cólera mediante truenos y rayos y su tranquilidad con el arco iris.

Los nepalíes veneran a Matsyendranatha como dios protector y aportador de las lluvias. En Australia los arunta veneraban al dios totémico Kararinjia, responsable de las lluvias.

Burroughs et alii (1998) señalan que la primera predicción de una secuencia de sequía se encuentra en el relato del sueño del Faraón incluido dentro del ciclo de José del libro del Génesis. Según esta leyenda el Faraón soñó que estaba junto al Nilo y de él «salían siete novillas de hermoso aspecto y bien cebadas, las cuales se pusieron a pacer en el juncal. Tras ellas he aqui que subian del Nilo otras siete novillas de mal aspecto y flacas de carnes, las cuales se pararon junto a las novillas primeras, a la orilla del Nilo. Luego las novillas de mal aspecto y flacas de carnes devoraron a las siete novillas de aspecto hermoso y bien cebadas». El Faraón soñó la misma secuencia pero esta vez con siete espigas gruesas y lozanas que eran devoradas por otras tantas delgadas y abrasadas por el solano. Inquieto por el significado de su sueño, el Faraón mandó llamar a José para que lo descifrase. Y José señaló que «el sueño del Faraón es uno solo. Elohim (Dios) ha manifestado al Faraón lo que va a realizar ...He aquí que van a venir siete años de gran abundancia en todo el país de Egipto. Tras ellos surgirán siete años de hambre, de suerte que se olvidará toda la abundancia en el país de Egipto, pues el hambre consumirá el país». José aconsejó al Faraón que acumulase el grano cosechado en los años de abundancia para poder tener alimento en los años de sequía. El relato concluye con la confirmación de dicha predicción y los beneficios que reportó el almacenamiento del grano pues «hubo hambre en todos los países, mientras en todo el país de Egipto había pan».

En relación con los mitos relativos a las nubes, los griegos veneraban las Hespérides, Ninfas hijas de Atlas y de Hespérida, que personificaban 
las nubes en el horizonte. El nombre procede del griego $\epsilon \sigma \pi \epsilon \rho o \zeta$ que significa la tarde. Con él se asocia el término Hespéria, «región de poniente», con el que los griegos designaban a Italia y que en el mito parece referirse a la península Ibérica.

Nefele es la nube creada por Zeus con semblante de la diosa Hera para engañar a Ixión, rey de los lapitas, que se había enamorado de la esposa del dios supremo. De la unión de Nefele con Ixión nacieron los centauros. En meteorología el conjunto de caracteres con que se nos presentan las nubes recibe el nombre de nefelismo y la reproducción fotográfica de éstas, nefoscopia. Los hindues veneran a los Marut, dioses védicos de las nubes y de la atmósfera. Sao-Tsing-Niang es la divinidad china de las nubes que tiene por misión esparcir por el cielo las nubes que portan lluvias y hacerlas regresar en los períodos de gran sequía. Yun-Tong era la deidad atmosférica china encargada de poner en fuga a las nubes del cielo.

El fenómeno óptico del arco iris encuentra también explicación en los relatos mitológicos. Así, Iris, hija de Taumante y de la ninfa Electra, mensajera de Zeus, es la personificación griega del arco iris. Se la representa como una bella mujer con alas y vestiduras multicolores rociada de gotas de agua en las que se refleja el Sol. Los romanos veneraban a Clara Dea, diosa luminosa, mensajera de Júpiter y de Juno. Pero, sin duda, la leyenda mitológica más bella referida al arco iris es la que se contiene en la mitología germánica, en la que el arco iris, llamado Bifröst, se asemeja a un puente oscilante creado por los dioses Ases nórdicos para unir el cielo y la tierra. Odín, dios supremo del panteón, vivía en la morada celeste de Asgardhr, que estaba unida a la Tierra por el puente Bifröst.

Otros fenómenos atmosféricos también tienen su deidad o sus héroes representativos en los diferentes panteones. Así, Haya Gi es el dios japonés del torbellino. $\mathrm{Hu}$-Sen es una divinidad menor china venerada como personificación del granizo. Taka-Okami es la deidad japonesa que domina las nieves. Osadagea es el dios del rocío de los iroqueses, que mitiga el calor de la tierra esparciendo rocío sobre ella. La explicación del rocío nos acerca al mito de Memnón, rey de Etiopía, hijo de la Aurora y de Titón. En la guerra de Troya, Memnón acudió en ayuda de su tío Príamo contra Aquiles, hijo de Tetis. Las dos diosas piden a Zeus suerte para sus hijos, pero Zeus pesa en una balanza los destinos de los dos héroes y sale perdiendo Memnón. Aquiles vence, pero Aurora obtiene de

$$
\text { - } 319-
$$


Zeus la inmortalidad de su hijo. La distinción concedida a su hijo no pudo, sin embargo, mitigar las penas de Aurora, que desde entonces no ha dejado de derramar lagrimas que forman el rocío que refresca los campos al amanecer.

El fuego de San Telmo está representado en el mito de los héroes griegos Cástor y Pólux, hijos de Zeus y Leda, que acompañaron a Jasón, como Argonautas, en su periplo a la Cólquide. En el viaje, inmersos en una violenta tempestad, los Argonautas advirtieron cómo unas llamas extrañas revoloteaban sobre la cabeza de los dos hermanos, al tiempo que el cielo se serenaba y amainaba la tormenta. Estas llamitas que se desarrollan, en ocasiones, en la punta de los mástiles durante las tempestades, conocidas comofuegos de San Telmo, reciben, asimismo, el nombre de fuego de Cástor y Pólux.

Del mito a la explicación racional

de los fenómenos atmosféricos

Dejando al margen a los pueblos primitivos que aún en la actualidad permanecen en las etapas primeras de aculturación, en el mundo occidental el paso de las narraciones mitológicas a la explicación racional de fenómenos atmosféricos se producirá a partir del siglo IV a J. C. con los trabajos de la Escuela de Mileto. Fierro (1991) habla de etapa «mito-meteorológica» para denominar este amplio período que registra, por contra, escasos avances en el conocimiento de los elementos y fenómenos climáticos. Esta afirmación conviene tanto a la civilización oriental como a la occidental. Baste recordar, como ejemplo prototípico, la mezcla de observaciones y referencias mitológicas que llenan la Ilíada, la Odisea o la propia obra de Hesíodo. Este último, propietario beocio, escribe en el siglo VII a. J. C. el poema épico Los trabajos y los días que, dirigido a su hermano Perseo, incluye una serie de consejos útiles a los labradores de su país. Estos consejos se resumen en un calendario del labrador plagado de referencias atmosféricas, desde el momento de la siega y la siembra en relación con la aparición y desaparición, respectivamente, de las estrellas Pléyades, la vestimenta apropiada en época de labores agrarias («siembra desnudo, ara desnudo, siega desnudo si quieres llevar a cabo a su debido tiempo todos los trabajos de Deméter»), en relación con la estación del año en que se desarrollan las la- 
bores agrícolas -verano-, la realización de la poda en otoño «cuando el sol penetrante abandone su sudoroso ardor, en tanto el poderoso Zeus hace caer las lluvias de otoño", así como una serie de recomendaciones para las tareas agrícolas en cada una de las estaciones del año: «atiende cuando oigas la voz de la grulla (octubre) que desde lo alto de las nubes lanza su llamada cada año; ella trae la señal de la labranza y anuncia la estación del invierno lluvioso», «ara en primavera y si en verano le das una segunda vuelta, no te defraurará». Hesíodo aconseja protegerse del viento Bóreas en invierno porque con su soplo «gime entonces todo el bosque inmenso»; en primavera, señala que es necesario huir «de los asientos a la sombra y de la cama después del alba en tiempo de siega, cuando el sol quema la piel», por lo que aconseja levantarse al amanecer para que el labrador tenga tiempo suficiente para llevar a cabo todas las labores agrícolas. En verano debe recogerse el grano cuando aparezca la estrella Orión (a comienzos de julio) y en otoño, a mediados de septiembre, cuando aparezca la estrella Arturo, es necesario cortar los racimos y, tras airearlos durante quince días, verter «en jarras los dones del alegre Dionisio».

Hesíodo recomienda a su hermano Perseo la vida agrícola en contra a la marinera, en relación con la mayor inseguridad y peligros que ofrece el mar frente a las labores del campo; sea como fuere, Hesíodo aconseja la primavera y el verano como estaciones propicias para la temporada de navegación.

Junto a estas referencias incluidas en las obras de Homero y Hesíodo, para este período «mito-meteorológico» no cabe olvidar los comentarios sobre fenómenos meteorológicos contenidos en el Antiguo Testamento, las predicciones de los magos caldeos y babilonios sobre episodios astronómicos o atmosféricos o la estrecha relación existente entre la teología egipcia y la meteorología. También son numerosas las noticias que, al respecto, contienen documentos procedentes de las civilizaciones orientales. Así, la asociación de elementos climáticos con deidades es común en el rico panteón hindú (la diosa Indra, por ejemplo, gobierna el aire y las nubes). En este ámbito, el astrónomo Vahara-Mihira elaboró, en el siglo vi a. J. C., un calendario lunar con continuas referencias atmosféricas para proporcionar a los agricultores un almanaque meteorológico útil. No menos ricas son las noticias procedentes de la civilización china. En el Tso Chuan (654 a J. C.) hay menciones de observaciones atmosféricas, particularmente precisas en lo referente a la determinación de los solsticios 
y equinoccios y su relación con eventos atmosféricos, así como explicaciones de la forma de las nubes. Otro texto, Chou $\mathrm{Li}$, contiene la obligación de los funcionarios imperiales de observar las nubes y los vientos y de hacer presagios sobre el tiempo atmosférico. Destacadas son las referencias sobre la relación entre vientos y lluvia presentes en documentos de los siglo IV y III a. J. C. o la teoría sobre el ciclo del agua, descrito por Wang Chung, en su obra Lun Hêng, (siglo I a. J. C. ).

Es de resaltar que será a partir del siglo vi a. J.C, en el mundo griego, cuando se registre un notable esfuerzo de reflexión e interpretación racional de las causas de los fenómenos atmosféricos. En efecto, las obras de los pensadores presocráticos inauguran una nueva etapa en el conocimiento y explicación de los fenómenos de la naturaleza; por vez primera, sus teorías intentan explicar los sucesos naturales sin recurrir a mitos ni fuerzas sobrenaturales. El pensamiento se hace laico y prevalece la idea de necesidad, frente a la arbitrariedad divina de la etapa anterior, en la explicación de los hechos. «Nada se produce porque sí, sino que todo surge por una razón y por necesidad», afirmará Leucipo en el siglo v a. J. C.

\section{BIBLIOGRAFÍA}

Alamillo, A. (1997): La Mitología en la vida cotidiana. Acento Editorial, Madrid, 89 pp. ARAto (s. III a. J. C.): Fenómenos, Ed. Biblioteca Clásica Gredos, Madrid, (1993), 148 pp. ARISTóteles (s. IV a. J. C. ): Los Meteorológicos, Alianza universidad, (introducción, traducción y notas de José Luis Calvo Martínez), Alianza Editorial, Madrid, 158 pp.

AujAC, G. (1966): Strabon et la science de son temps, Societe d'edition «Les Belles Lettres», París, pp. 147-170 y 267-273.

Braudel, F. (1998): Memorias del Mediterráneo, Ediciones Cátedra, Madrid, 381 pp.

Burroughs, W. J., Crowder, B., Robertson, T., Vallier-Talbot, E. Whitaker, R. (1998) Observar el Tiempo. Ed. Planeta, Barcelona, $288 \mathrm{pp}$.

Estrabón (1980): Geografía. Prolegómenos. (Traducción y notas por Ignacio Granero; Introducción por Arturo A. Roig). Ed. Aguilar, Madrid, $477 \mathrm{pp}$

- (1991): Geografía. Libros I-II. (Introducción general de J. García Blanco; Traducción y notas de J. L. García Ramón y J. García Blanco). Biblioteca Clásica Grados. Madrid, $559 \mathrm{pp}$.

Fierro, A. (1991): Histoire de la météorologie. Ed. Denoel, Paris, 315 pp.

García GuAL, C. (1988): «Estudio preliminar» en Escritos platónicos. Espasa Calpe, Madrid.

GÉmino (s. I a. J. C.): Introducción a los fenómenos, Ed. Biblioteca Clásica Gredos, Madrid, (1993):, $168 \mathrm{pp}$.

GLACKEN, C. J (1996): Huellas en la playa de Rodas. Naturaleza y cultura en el pensamiento occidental desde la Antigüedad hasta finales del siglo XVIII. Ediciones del Serbal, Barcelona, 729 pp. 
GriBBIn, J. y M. (1992): Hijos del hielo. Clima y origenes del hombre. Ediciones Pirámide, Madrid, $215 \mathrm{pp}$.

GRIGORIEFF, V. (1998): Mitologías occidentales. Ed. Robin Book, Barcelona, 247 pp.

HUBERT, J. (1997): Mitología griega y romana, Ed. Gustavo Gili, Barcelona, 311 pp.

LAMB, H. H. (1979): Climate: Present, past and future. Methuen, London and New York, 2 vols. 613 y 835 pp.

Montet, P. (1996): La vida cotidiana en Egipto en tiempos de los Ramses. Ediciones Temas de Hoy, Madrid, $414 \mathrm{pp}$.

Pedech, P. (1976): La géographie des grecs. P.U.F., París, 202 p.

PINNA, M. (1988): La teoria dei climi. Una falsa dottrina che nos muta da Ipocrate a Hegel. Società Geografica Italiana. Roma, $395 \mathrm{pp}$.

Plinio El VIeJo (s. I d. J. c. ): Historia Natural. Libros I a VI. Biblioteca Clásica Gredos n ${ }^{\circ}$ 206 y 250 , Madrid, 484 y $539 \mathrm{pp}$.

Sechi MesticA, G. (1993): Mitología Universal. Diccionarios Akal. Ediciones Akal, Madrid, $616 \mathrm{pp}$.

SPENCE, L. (1997): Introducción a la Mitología, M. E. Ediciones, Madrid, 341 pp.

STASZAK, J. F. (1994): «Quand les Grecs se moquaient des météorologues...», La Météorologie, $8^{\mathrm{e}}$ série, $\mathrm{n}^{\circ} 7$, pp. 69-76.

(1995): La géographie d'avant la géographie. Le climat chez Aristote et Hippocrate, Ed. L'Harmattan, Paris, $252 \mathrm{pp}$.

Wigley, T. M. L., INGRAM, M. J. y FARMER, G. (1981): Climate and History. Studies in past climates and their impact on Man. Cambridge University Press, Cambridge, $530 \mathrm{pp}$.

RESUMEN: Las sociedades primitivas, en los estadios primeros de civilización han buscado explicación a los hechos de la naturaleza. Entre estos la interpretación de los signos de cielo ha ocupado una papel fundamental. Por lo demás, los panteones suelen estar presididos por una divinidad principal de la que depende la propia acción solar u otros fenómenos atmosféricos significativos. En el mundo occidental la aparición de las ideas de los presocráticos, en el s. VI a. J. C., marcará el final de la interpretación mitológica de los fenómenos meteorológicos

PALABRAS CLAVE: Mitos, leyendas, fenómenos atmosféricos, interpretación racional.

ABSTRACT: Primitive societies, in the early hases of civilization, have found explanation to the facts of the Nature. In this matters, interpretarion of sky signs has occupied a principal place. Mithological pantheons ussually are presided at a principal divinity who is a solar deity or significant atmospheric phenomena deity. In occidental world presocratic philosophers end mithological interpretarion of meteorological facts.

KEY MOTS: Miths, legends, atmospheric facts, rational interpretarion. 